\title{
Diabetes mellitus and hypertension: the possible role of hyperglycaemia through oxidative stress
}

\author{
A. Ceriello ${ }^{1}$, A.Quatraro ${ }^{2}$ and D. Giugliano ${ }^{3}$ \\ ${ }^{1}$ Istituto di Patologia Clinica e Sperimentale, Cattedra di Medicina Interna, Facoltà di Medicina, Università di Udine, Udine, Italy \\ ${ }^{2}$ Centro di Diabetologia, Casa di Cura S. Rita, Taranto, Italy \\ ${ }^{3}$ Cattedra di Malattie del Metabolismo, I Facoltà di Medicina, Università di Napoli, Napoli, Italy
}

It is estimated that $30 \%$ of the adult population may have arterial hypertension [1], and that $30-60 \%$ of diabetic patients have associated hypertension [2]. A series of observations has provoked much speculation and interest in the phenomenon of insulin resistance as a common factor underlying the link between obesity, diabetes mellitus and hypertension [3].

Epidemiological data linking hyperinsulinaemia, obesity and hypertension seem to be associative rather than causal, but this is inconsistent [4]. It has become increasingly evident that the relationship between insulin, insulin-resistance and blood pressure varies according to racial group [5]. On the other hand, chronic and marked hyperinsulinism in patients with insulinomas is not associated with elevated blood pressure values [6]. Although the causal relationship between insulin and blood pressure is still inconclusive, recent evidence suggests that a reduced hepatic insulin clearance may contribute to increased insulin levels in hypertension [7, 8]. To summarize, current experimental findings linking hyperinsulinaemia or insulin resistance to hypertension have been provocative: many inconsistencies remain and causal relationships have not been established.

Although diabetes is a well-established risk factor for macrovascular disease, the role of hyperglycaemia is less clear, perhaps because a strong relationship between glucose levels and cardiovascular risk factors has not been consistently found [9]. However, evaluating the relationship between $\mathrm{HbA}_{1 \mathrm{C}}$ and cardiovascular disease in the survivors of the original cohort of the Framingham Heart Study, Singer et al. [10] found that $\mathrm{HbA}_{1 \mathrm{C}}$ was significantly related to prevalent cardiovascular disease among women but not men. We found a positive correlation between $\mathrm{HbA}_{1 \mathrm{c}}$ and established risk factors for cardiovascular disease, particularly systolic blood pressure and total cholesterol [11]. This may indicate that the impact of hyperglycaemia on cardiovascular risk factors may be stronger than previously thought.

It is now well-established that a reduction of anti-oxidant defence is an important cardiovascular risk factor [12] and much evidence has been accumulated indicating that an increased free radical generation is present in diabetes [13,14], hyperglycaemia and non-enzymatic glycation of proteins themselves being important sources of free radicals $[15,16]$.

Endothelial cells play a major role in arterial relaxation. The factor released by the endothelium that causes vascular relaxation is called endothelium-derived relaxing factor, and nitric oxide is believed to be one such factor [17]. The half-life of nitric oxide is only a few seconds since it is rapidly degraded by the oxygen-derived free radical superoxide anion. An imbalance of this system has been hypothesized to play a role in the development of arterial hypertension [18]. Since an increased serum superoxide generation, correlated with glucose and glycated protein plasma levels has been found in diabetic subjects [19], the raised prevalence of hypertension in diabetes might be linked to this increased generation of free radicals. This hypothesis is supported by the following observations: glucose alters some endothelial cell functions through free radicals [20], free radicals specifically abolish endothelium-dependent relaxation in the aorta of diabetic and hypertensive rats [21,22], an anti-oxidant deficiency in the diet contributes to the aetiology of hypertension in populations [23], an elevated plasma glucose concentration impairs endothelium-dependent relaxation in the rabbit [24], anti-oxidant drugs ameliorate the abnormal arterial vasomotion in diabetes [25] and also show a blood pressure lowering effect in both diabetic and hypertensive subjects [26].

Many studies have confirmed the existence of a genetic contribution to the determination of blood pressure [27]. In this respect, the balance between hyperglycaemia and the different, genetically-determined anti-oxidant cellular defence may account for a different effect of hyperglycaemia-related increased free radical production in the development of hypertension in diabetic patients. This point of view is supported, for example, by the evidence that, in carcinogenesis, the genetically-determined level of cellular anti-oxidant defences may condition the neoplastic tranformation of cells induced by the free radicals [28]. 
Although more than one factor is probably implicated in the development of hypertension in diabetes, the present hypothesis puts in perspective the crucial role of glucose in the aetiology of diabetic complications [29]. Antioxidants have blood pressure lowering effects [26] and also reduce one source of free radicals, protein glycation [30]. Anti-oxidant supplementation might be advantageously used to support anti-hypertensive therapy in diabetic patients.

\section{References}

1. Haber H (1985) Hypertension - where do we go from here? Hypertension 7: 311-312

2. Drury PL (1983) Diabetes and arterial hypertension. Diabetologia $24: 1-9$

3. Reaven GM (1991) Insulin resistance, hyperinsulinemia, and hypertriglyceridemia in the etiology and clinical course of hypertension. Am J Med 90 [Suppl 2A]: 7-12

4. Izzo JL, Swislocki ALM (1991) Workshop III - Insulin resistance: is it truly the link? Am J Med 90 [Suppl 2A]: 26-31

5. Saad MF, Lillioja S, Nyomba BL et al. (1991) Racial differences in the relation between blood pressure and insulin resistance. $\mathrm{N}$ Engl J Med 324: 733-739

6. O'Brien T, Young WF, Palumbo PJ et al. (1991) Is the hyperinsulinaemia of insulinoma associated with hypertension and hypertriglyceridemia? Diabetologia 34 [Suppl 2]: $19 \mathrm{~A}$

7. Salvatore T, Cozzolino D, Giugliano D et al. (1992) Decreased insulin clearance as a feature of essential hypertension. J Clin Endocrinol Metab 74: 144-149

8. Giugliano D, Salvatore T, Paolisso G et al. (1992) Impaired glucose metabolism and reduced insulin clearance in elderly hypertensives. Am J Hyperten 5: 345-354

9. Kannell WB, McGee DL (1979) Diabetes and cardiovascular disease: the Framingham Study. JAMA 241: 2035-2038

10. Singer DE, Nathan DM, Anderson KM et al. (1992) Association of $\mathrm{HbA}_{1 \mathrm{C}}$ with prevalent cardiovascular disease in the original cohort of the Framingham Heart Study. Diabetes 41: 202-208

11. Giugliano D, Quatraro A, Minei A et al. (1992) Does a positive history of diabetes convey a more atherogenetic blood profile? Diabetologia 35 [Suppl 1]: A93 (Abstract)

12. Gey FK, Puska P, Jordan P, Moser UK (1991) Inverse correlation between plasma vitamin $\mathrm{E}$ and mortality from ischemic heart disease in cross-cultural epidemiology. Am J Clin Nutr 53: 326-334

13. Baynes JW (1991) Role of oxidative stress in development of complications in diabetes. Diabetes 40: 405-412

14. Ceriello A, Quatraro A, Giugliano D (1992) New insights on non-enzymatic glycosylation may lead to therapeutic approaches for the prevention of diabetic complications. Diabetic Med 9: 297-299
15. Hunt SV, Dean RT, Wolff SP (1988) Hydroxyl radical production and autoxidative glycosylation. Glucose autoxidation as the cause of protein damage in the experimental glycation model of diabetes mellitus and ageing. Biochem J 256: 205-212

16. Sakurav T, Tsuchiya S (1988) Superoxide production from nonenzymatically glycated proteins. FEBS Lett 236: 406-410

17. Vallance P, Collier J, Moncada S (1989) Effects of endotheliumderived nitric oxide in the regulation of blood pressure. Lancet II: $997-1000$

18. Vanhoutte PM (1989) Endothelium and control of vascular function. Hypertension 13:658-667

19. Ceriello A, Giugliano D, Quatraro Aet al. (1991) Metabolic control may influence the increased superoxide anion generation in diabetic serum. Diabetic Med 8: 540-542

20. Curcio F, Ceriello A (1993) Decreased cultured endothelial cell proliferation in high glucose medium is reversed by antioxidants: new insights on the pathophysiological mechanism of diabetic vascular complications. In Vitro, in press

21. Pieper GM, Gross GS (1988) Oxygen free radicals abolish endothelium-dependent relaxation in diabetic rat aorta. Am J Physiol 254: $\mathrm{H} 825-\mathrm{H} 833$

22. Auch-Schwalk W, Katusic ZS, Vanhoutte PM (1989) Contractions to oxygen-derived free radicals are augmented in aorta of the spontaneously hypertensive rat. Hypertension 13: 859-862

23. Salonen JT, Salonen R, Thanainem M et al. (1988) Blood pressure, dietary fats, and antioxidants. Am J Clin Nutr 48: 1226-1232

24. Tesfamariam B, Brown ML, Cohen RA (1991) Elevated glucose impairs endothelium-dependent relaxation by activating protein kinase C. J Clin Invest 87: 1643-1648

25. Ceriello A, Quatraro A, Caretta F et al. (1990) Evidence for a possible role of oxygen free radicals in the abnormal functional arterial vasomotion in insulin dependent diabetes. Diabete Metab 16: 318-322

26. Ceriello A, Giugliano D, Quatraro A, Lefebvre PJ (1991) Antioxidants show an anti-hypertensive effect in diabetic and hypertensive subjects. Clin Science 81: 739-742

27. Anonymous (1992) Genetics of hypertension. Lancet I: 1142 1143

28. Cerutti PA (1991) Oxidant stress and carcinogenesis. Eur J Clin Invest $21: 1-5$

29. Ceriello A, Giugliano D, Quatraro A, D'Onofrio F (1988) Does a common mechanism induce the diverse complications of diabetes? Diabetes Care 11: 372-373

30. Ceriello A, Giugliano D, Quatraro A et al. (1991) Vitamin E reduction of protein glycosylation in diabetes. New prospect for the prevention of diabetic complications? Diabetes Care 14: 6872

Dr. A. Ceriello

Cattedra di Medicina Interna

Facoltà di Medicina, Università di Udine

P.le S. Maria della Misericordia

I-33100 Udine

Italy 